\title{
The Design and Simulation of Sloping Channel Stabilization Loop
}

\author{
T.Y. Wulan \\ School of Information Science and Technology, Baotou \\ Normal University, Inner Mongolia
}

China

L.H. Wang

School of Mathematical Science, Baotou Normal University, Inner Mongolia

China

\begin{abstract}
This paper analyzes the main problems and technical requirements of sloping channel stabilization loop design, in order to make the static error of slope stability not big and reduce the sensitivity of "time-varying interference moment of couple" in the system, the integral correction is introduced. In parameter design, the method of describing function is used to studty, design and optimize in frequency domain repeatedly. Mainly it is discussed for the flight speed at $24 \mathrm{~m} / \mathrm{s}$ and $300 \mathrm{~m} / \mathrm{s}$, and given the corresponding frequency characteristics of the open-loop linear part in sloping channel stabilization loop, and there is a stable self sustaining oscillation points. According to the design results of sloping channel stabilization loop, using six degrees of freedom rigid body trajectory to do simulation experiment, the results show that the principle design and parameter design of sloping channel stabilization loop meet the technical requirements.
\end{abstract}

Keywords-sloping channe; stabilization loo; moment of couple; describing function; simulation

\section{INTRODUCTION}

The main problems of Sloping channel stabilization loop design : under the action of a larger interference torque ,achieved stable at a high enough precision; under the condition of the rapid drop of elevation angle in the initial flight period, ensured to finish the adjustment to the missile pitch yaw attitude in a short time; under the condition of the missile pitch yaw channel parameters changing dramatically, maked missile on the response to the control instruction have a certain consistency.

\section{SLOPING CHANNEL STABILIZATION LOOP DESIGN}

A. The Basic Technical Requirements of Sloping Channel Stabilization Loop Design

The ideal state of slope stability is making the surface of the body coordinate system $O x_{b} y_{b}$ vertical to the surface of platform coordinate system $O x_{p} z_{p}$, that is, its tilt angle $\gamma$ is zero[1].

\author{
R.J. Li \\ Department of Computer, Jining Teachers’ College, Inner \\ Mongolia \\ China
}

W.Z. Yun

School of Mathematical Science, Baotou Normal University, Inner Mongolia

China

It is assumes that the missile in $1.5 \mathrm{~m}$ above the target, in order to leave a margin, the warhead point error is not more than $0.15 \mathrm{~m}$, which caused by static error of slope stability. From the above assumptions,we can calculate to obtain static error of slope stability is $\gamma< \pm 5^{\circ}$.

It is assumed that the adjustment time of pitch yaw attitude after missile out of barrel can't be more than $0.5 \mathrm{~s}$. We hope that when pitch yaw attitude adjustment is complete [2], slope channel has reached a stable state, and then determine he adjusting time of the slope channel loop is $t_{s}<0.5 \mathrm{~s}$.

\section{B. Design Principle of Slope Channel Loop}

To control the missile tilt of the moment of couple for input channel see type projectile link transfer function, can be seen in Eq.1.

$$
\frac{\gamma}{M_{c d x}}=\frac{K_{d x}}{S\left(T_{d x} S+1\right)}
$$

Where $S$ is the laplacian, $M_{c d x}$ is the sloping channel output of the steering gear control moment of couple, $K_{d x}=\frac{1}{b_{2}}, T_{d x}=\frac{b_{1}}{b_{2}} . b_{1}, b_{2}$ is the dynamic coefficient, $b_{1}=J_{x}, b_{2}=-\frac{1}{4} \rho v S l^{2} m_{x}^{\bar{\omega}_{x}}, J_{x}$ is the missile of moment of inertia ( $J_{x}=J_{x_{b}}$ ), $l$ is the reference length of the projectile horizontal, $m_{x}^{\bar{\omega}_{x}}$ is the derivative of tilt damping, $\bar{\omega}_{x}=\frac{\omega_{x} l}{2 v}$ is the dimensionless velocity, $\omega_{x}$ is the missile angle velocity, thus, we have $\omega_{x}=\omega_{i b x}^{b}$.

The slope channel circuit block diagram is shown in Fig. 1. After discretization by "Sampling-Zero Order Holder", 
we can generate the control command by the on-missile computer.

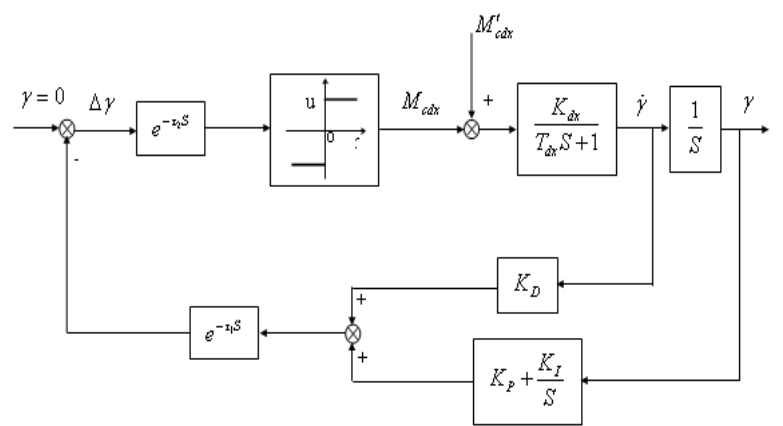

FIGURE I. SLOPE CHANNEL STABILIZATION LOOP DIAGRAM

In Fig. 1, the steering engine is signed as relay, $M_{c d x}^{\prime}$ is the sloping channel interference moment of couple, $K_{D}$ is the angular velocity feedback channel transfer coefficient, $K_{P}+\frac{K_{I}}{S}$ is the slope angle feedback correction network channels, $e^{-\tau_{1} S}$ is the instruction computing delay link, $\tau_{1}$ is the slope channel command delay time, $e^{-\tau_{2} S}$ is the steering gear delay link, $\tau_{2}$ is the slope channel servo delay time, $\Delta \gamma$ is the tilt angle error angle. $K_{P}, K_{I}$ and $K_{D}$ are the parameters to design[3].to reduce the system sensitivity to the time-varying interference moment of couple, we introduce integral compensation.

We assume that the speed of the missile launch without power is less than $25 \mathrm{~m} / \mathrm{s}$, the maximum value is nearby $300 \mathrm{~m} / \mathrm{s}$. According to the above assumption, the following design work is in view of the two speed feature points which are $24 \mathrm{~m} / \mathrm{s}$ and $300 \mathrm{~m} / \mathrm{s}$.

The phase lag computational formulation which is caused by Zero-Order holder can be seen in Eq. 2.

$$
\Phi_{(\mathrm{ZOH})}=180 \cdot f / f_{s}
$$

where $\Phi_{(\mathrm{ZOH})}$ is the phase lag which is caused by ZeroOrder holder ${ }^{o}$ ); $f$ is the frequency of the input signal $(1 / \mathrm{s}) ; f_{s}$ is the sampling frequency $(1 / \mathrm{s})$ 。

The phase lag computational formulation which are caused by instruction computing delay and steering gear delay can be seen in Eq.3.

$$
\Phi_{(D E L A Y)}=360 \cdot f \cdot \tau_{d}
$$

where $\Phi_{(D E L A Y)}$ is the phase lag which are caused by instruction computing delay and steering gear delay $\left({ }^{o}\right) ; \tau_{d}$ is the total delay.
On the basis of above data and formulation, we study the model by describing function method[4]. By repeatedly frequency domain design and

optimization, we finally denote that
$K_{P}=1.5, K_{I}=9.0, K_{D}=0.1$.

When the flight speed of the guided missile is $24 \mathrm{~m} / \mathrm{s}$, the open and linear part frequency characteristics of slope channel stabilization loop is shown in Fig. 2. When the speed is $300 \mathrm{~m} / \mathrm{s}$, the frequency characteristic is shown in Fig. 3.

From the figure 2 and figure 3, it can be seen that there is a stable self sustaining oscillation points, when the flight speed is $24 \mathrm{~m} / \mathrm{s}$, the self sustaining oscillation frequency is $186 \mathrm{rad} / \mathrm{s}=29.6 \mathrm{~Hz}$; When the flight speed is $300 \mathrm{~m} / \mathrm{s}$, the self sustaining oscillation frequency is $189 \mathrm{rad} / \mathrm{s}=30.1 \mathrm{~Hz}$.

Considering the calculation results of figure 2 and figure 3 is to simplify the steering gear into ideal relay, in the actual situation ,aerodynamic data and the transfer function will also change[5], and the research methods of used here is describing function method.

When missile launch, because of various disturbance, the slope angle may be larger, if immediately introduced Angle integral link in the slope stability loop, which may lead to overshoot increase[6]. Considering the adjustment time is not more than $0.5 \mathrm{~s}$, then it is determined that the Angle integral link is introduced for $0.5 \mathrm{~s}$ after the missile launch,valued $K_{I}=0.0$ before $0.5 \mathrm{~s}$.
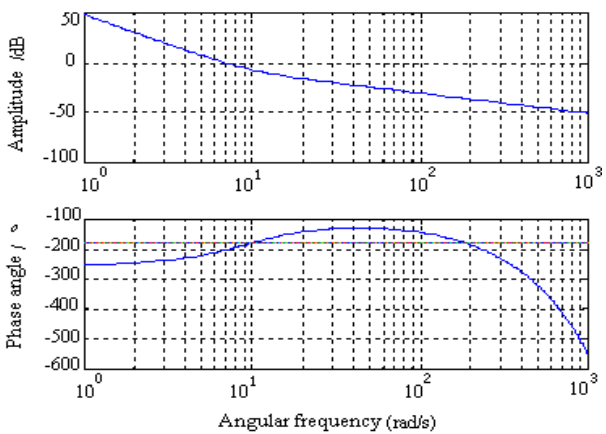

FIGURE II. SPEED AT 24M/S THE FREQUENCY CHARACTERISTICS
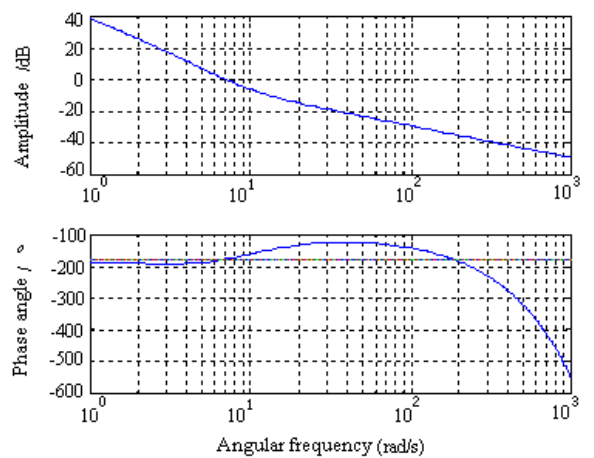

FIGURE III. SPEED AT 300M/S THE FREQUENCY CHARACTERISTICS 
Before $0.5 \mathrm{~s}$, valued $K_{P}=1.5 、 K_{I}=0.0 、 K_{D}=0.1$. At the moment, the missile flight speed is about $24 \mathrm{~m} / \mathrm{s}$, the slope channel stability loop open-loop frequency characteristics of the linear part as shown in Fig. 4.
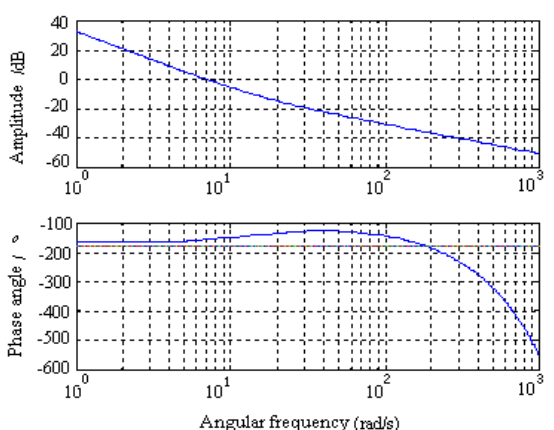

FIGURE IV. BEFORE 0.5S THE FREQUENCY CHARACTERISTICS

As it can be seen from the figure 4, there is a stable self sustaining oscillation points, self sustaining oscillation frequency is $186 \mathrm{rad} / \mathrm{s}=29.6 \mathrm{~Hz}$.

\section{SLOPE STABLE LOOP SIMULATION TEST}

According to the result of the above design, we can use six degrees of freedom rigid body trajectory to carry out simulation experiment [7].

When initial Angle of the missile is $-18 \cdot 3^{\circ}$, and interference moment of couple is zero, the controlled change process of the slope Angle is shown in Fig.5,and $0.5 \mathrm{~s}$ control moment of couple as shown in Fig .6.

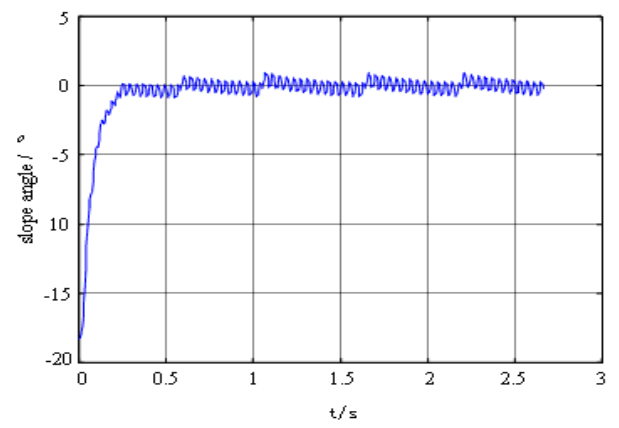

FIGURE V. HANGING PROCESS OF ANGLE CONTROLLED WHILE INTERFERENCE MOMENT OF COUPLE IS ZERO.

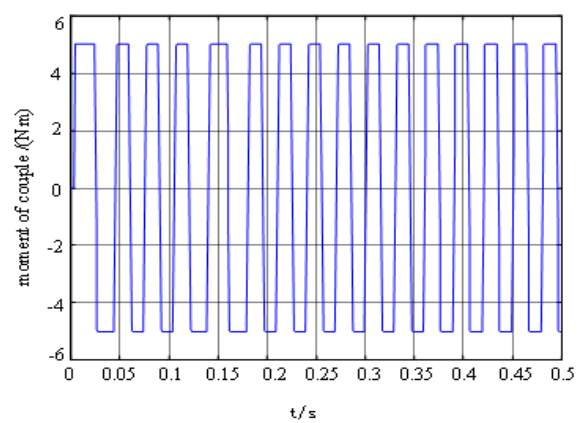

FIGURE VI. THE MOMENT OF COUPLE OF MISSILE FLIGHT CONTROLLED IN 0.5S
The simulation results show that the steering gear working frequency is between $27 \sim 32(\mathrm{~Hz})$, adjustment time is less than $0.5 \mathrm{~s}$, and control process meet the requirements.

When the missile initial Angle is -18.3 , missile flight time $t=0 \sim 1.315$ (s), interference moment of couple changes with $-2.5 \times t$; After $t>1.315 \mathrm{~s}$, interference moment of couple changes into constant $0.2 \mathrm{Nm}$. slope Angle controlled change process as shown in Fig. 7.

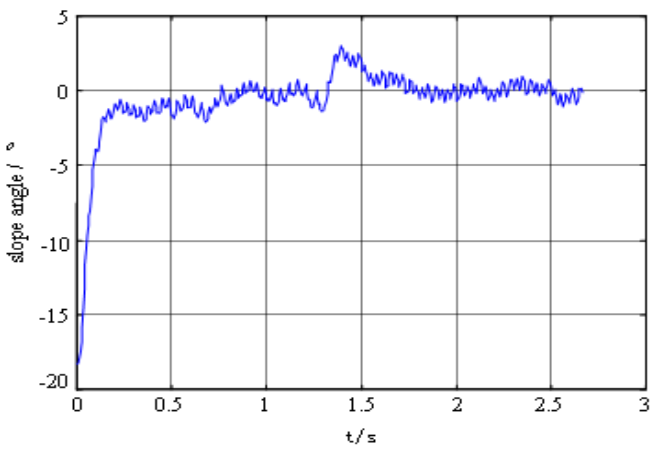

FIGURE VII. CHANGING PROCESS OF ANGLE CONTROLLED IN THE CASE OF TIME-VARYING INTERFERENCE MOMENT OF COUPLE.

From the simulation results, steering gear working frequency is between 24 and $33(\mathrm{~Hz})$, adjustment time is less than $0.5 \mathrm{~s}$, control process meets requirements[8].

Figure 7 is the simulation results of a time-varying interference moment of couple under severe change, the disturbance moment of couple's largest value reaches -3.3 $\mathrm{Nm}$, and then suddenly becomes into $0.2 \mathrm{Nm}$, but control system still meets the requirements [9].

Simulation experiment results show that the principle design and parameter design of Sloping channel stabilization loop meet the technical requirements.

\section{REFERENCE}

[1] Meng Xiuyun. Principle of missile guidance and control system. Beijing Institute of Technology Press, pp. 120-183, 2003.

[2] Chien Y Huang, Gareth J Knowles1 Application of nonlinear control strategies to aircraft at high angle of attack 1 Proc1 of the 29th Conference on Decision and Control, pp. 188-193, 1990.

[3] Wang Zongxue. Introduction to aircraft control system. Beijing University of Aeronautics and Astronautics Press, pp. 28-45, 1993.

[4] Zhang Limin. Automatic control principle. Science Press, pp. 98-132, 2014.

[5] Bai Tao. Super short range anti-tank missile overall design . Journal of Beijing institute of Technology University Degree Paper, pp. 13-21, 2001.

[6] KeWei. Design of missile stable loop Attitude based on QFT design. Journal of Tactical Missile Control Technology, 31(1),pp. 29-32, 2009.

[7] Li Mingan. Modeling and simulation of dynamic system. National Defense Industry Press,pp. 104-110,287-310, 2012.

[8] Jacob Reiner, Gary J Balas, William L Garrard 1Flight con2Trol Design using robust dynamic inversion and time2 scale separation IEEE Transactions on Automatic ontrol, pp. 1493-1504, 1994.

[9] Song Zhenduo. Demonstration and testing of anti-tank guided weapons. National Defense Industry Press,pp. 251-262, 2003. 